\title{
Participatory foresight and reflexive innovation: setting policy goals and developing strategies in a bottom-up, mission-oriented, sustainable way
}

\author{
Aaron B. Rosa ${ }^{*} \mathbb{D}$, Simone Kimpeler, Elna Schirrmeister and Philine Warnke
}

\begin{abstract}
The urgency of current social challenges is driving new approaches to framing and funding research, development, and innovation. The "mission-oriented" approach framing the EU's New Horizons funding program is the latest institutional response to the pressing needs of large system transformations we are facing. We view the likely targets of mission-oriented programs as dynamic entities requiring both adaptive, inclusive responses, and anticipatory exploration. We demonstrate how participatory foresight methods provide an essential forum and process for the expression of plural, socio-technological imaginaries. As citizens and other stakeholder groups have demonstrated their myriad capacities to contribute to research and innovation agenda-setting processes in futureoriented citizen dialogs, we argue that such methods are the essential compliment to the mission-oriented framework coming into play. Participatory foresight engages citizens in critical thinking and creative activities to articulate the evolution of socio-technological issues over an extended time horizon, seeking diverse perspectives on what goals and priorities will come to define "missions." Utilizing outputs from two recent projects, we argue that participatory foresight methods can play an essential role in bridging citizen needs with policy requirements, and will increase the reflexivity of innovation systems that invest the needed time and resources into exploring the depth of multi-actor interests and intersections. Finally, we outline possible impact pathways demonstrating how these "bottom-up" contributions could be integrated into the development of challenge-led innovation priorities.
\end{abstract}

Keywords: Participatory foresight, Citizen visioning, Future dialogue, Reflexive innovation systems, Co-creation

\section{Introduction}

Finding solutions for the long-term Grand Challenges that face humanity remains a key driving force in developing new approaches to the organizing and funding of responsible research and innovation. The "mission-oriented" framing of the EU's New Horizons funding scheme is one of the latest institutional embodiments of the pressing challenges we are facing in order to provide sustainable perspectives to future generations. The approaching launch of the next European Framework Program-Horizon

\footnotetext{
* Correspondence: Aaron.rosa@isi.fraunhofer.de

Fraunhofer Institute for Systems and Innovation Research (ISI), Karlsruhe, Germany
}

Europe (FP9) - has been accompanied by a surge in public funding for RDI into challenge-led innovation framework [43], and shifted criteria by which projects are formulated and selected. The concept argues valiantly for increasing public engagement in R\&I governance and processes (e.g., priority-setting, collaborative innovation) in ther than reactive, innovation agendas [36, 86]. The still-inuse "moonshot" metaphor, derived from the Apollo 
missions, for disruptive innovation solving grand challenges is framing R\&I policy, and obscuring the threat that demand-orientation might embed the R\&I agendasetting process within a technocratic economic policy that ultimately fails to address citizen needs. To counter the possibility of procedural capture by vested interests, participatory selection processes have been emphasized as a mode by which "missions" can be defined and prioritized by and for a diverse public [43].

A deluge of reports from international organizations reminds us that the EU and nations around the world currently face core, systemic challenges in the form of climate change, environmental degradation, demographic shifts, and resource scarcity among others. This implies that people worldwide all face the same challenges, but these systemic challenges manifest themselves in ways that are highly contingent on local actors and socio-political conditions, and this "bottom-up" perspective-wildly variable as it may be-has been consistently underrepresented in high-level policies directed at systemic change. By downplaying or ignoring localized conditions, supranational governing institutions risk alienating or disenfranchising the public whose support is necessary for the attainment of high-level goals. The sustainable development goals (SDGs) are an example of how these conditions shape governments' decision-making [75], given the different stages of addressing the SDGs present within the EU member states, and the different ways that nations and communities around the world prioritize the SDGs [48]. As Mazzucato rightly points out, the SDGs, and the Millennium Goals [76] that preceded them, have consistently defined "missions"-goals that are focused on creating ambitious change in the lives and basic rights of people around the world. She, and others, have also consistently called for mission setting processes that are inclusive of the broader public and their diverse hopes, anxieties, and aspirations.

With this article, we demonstrate that bottom-up participatory, inclusive foresight activities-for example, future-oriented dialogs with citizens, story-telling workshops for narrative generation, and citizen visioning processes-can serve transitioning processes inherent in "mission" achievement.

Through the examination of two recent participatory foresight exercises, we provide evidence of the innovationcentered outputs of participatory foresight. These are outputs that either take a particular social or technological innovation as the subject of future-oriented speculation, or that might utilize multiple innovations in novel, generative combinations to give texture and narrative to alternative futures. In either mode, these outputs provide the basis for mission-oriented, innovation policy-making wherein these aspects of social embeddedness are crucial to deepening policy considerations. Further, we suggest ways that participatory processes and products can be successfully coupled to bolster reflexivity in innovation systems. The CIMULACT ${ }^{1}$ project, running from 2015 to 2018, was a European project focused on developing citizen visions for sustainable communities, and translating those visions into actionable policy. The BioKompass project running from 2017 to $2020^{2}$ is a regional project, engaging citizens in a scenario development process that serves as a foundation for a public engagement exhibition at the Senckenberg Naturmuseum with the ultimate goal to underpin a transition toward a sustainable bioeconomy. Through artefacts that were created during these projects' participatory methods (scenarios, narratives, personas, etc.), citizens articulate diverse perspectives with regard to 'mission' goals and their long-term impacts. As described below, this allows for a deeper understanding of problem areas and challenges with demand-driven innovation policies as reflected in the outputs of citizen engagement activities.

This article is structured to articulate our understanding of participatory foresight's role in a mission-oriented approach to R\&I agenda creation, and advocating the methodology as a mode of engendering greater reflexivity in innovation approaches. Our article first provides a definition of participatory foresight that recognizes the historical evolution of the methods and contexts that the term encompasses, but reaffirms an understanding of participation that focuses on citizen engagement activities that create future-oriented artefacts (scenarios, narratives, visions, etc.) in a "bottom-up" fashion. We view this citizen-focused mode of participatory foresight as a key element of bolstering reflexivity in the process of establishing mission-oriented policy. To further support this position, the article continues with a review of reflexive innovation systems literature that opens itself to future-oriented methodological approaches.

We then examine the outputs of two participatory foresight projects-noting unique and complimentary positions that emerge from participatory activities in light of otherwise top-down policy-making procedures, and locating their utility within these governing contexts. Central to our position, is an examination of the artefacts that are produced during these project's participatory foresight processes in which we establish their capacity to voice perceived and desired societal impacts of innovation directed at mission goals. In our analysis, we demonstrate through an examination of these artefacts, the modes through which participatory foresight processes can serve to bolster the legitimacy of

${ }^{1}$ CIMULACT was funded by the European Commission Horizon 2020 project. Grant Agreement number 665948. http://www.cimulact.eu/ ${ }^{2}$ BioKompass was funded by the German Ministry of Research and Education and carried out by Fraunhofer ISI together with Fraunhofer ICT and IGD, Senckenberg Naturmuseum, and Institute for SocioEcological Research ISOE. 
"mission-oriented" policy by creating a future-oriented, reflexive mechanism through which innovation policy can be sensitized to, and reflective of, citizen aspirations. Accordingly, our analysis section is organized to address three primary questions of interest with respect to understanding participatory foresight within a missionoriented innovation policy:

- What are the specific qualities of citizen-based visions and artefacts?

- What is the added value of these qualities for establishing mission-oriented policy?

- What are potential inroads for the impact of citizen-based foresight artefacts?

\section{Bottom-up participatory foresight toward mission making: citizens generating futures artefacts}

We define the term participatory foresight as an approach to future-oriented activities that encourages integrated, citizen-focused engagement at multiple points in the foresight research process, and recognizes citizen-generated artefacts as an important mode of communicating "bottom-up" images of the future and their inherent citizen aspirations. In clarifying our understanding of "participation" as citizen-focused, we refer to documents from the term's genesis. Though originally developed for the planning context, Arnstein's Ladder of Citizen Participation [1] remains a useful, if incomplete, classification system for participatory processes. In our understanding, a process' emphasis on citizen perspective and creative inputs is an important differentiator between participatory approaches, opening modes of communicative influence that shape participation in complex governance [23]. In this light, we define participatory foresight as activities that encourage expanding channels for citizen inputs, and integrating them into the final project results. Particularly given the critique that has been levied at "participation" in the contexts of development [9], we view participatory foresight processes as enabling and fostering citizen influence with respect to longer-term futures. Through more citizen representation at critical project phases, and through process that enable citizens to shape a project's final products, citizen perspectives are given greater agency in follow up processes that utilize those products (policy-making, urban planning, etc.). This understanding of participation is also reflected in literature in participatory design $[30,62]$ and can be tied to the development of Action Research theory and method $[34,54,55,72]$. That participatory processes still grapple with issues relating to legitimation [63] (and representation with respect to "future generations" [49]), we view participatory foresight defined in this manner as a means to broaden the scope of possible futures on behalf of those generations while expanding procedural legitimacy in the present.

We might further refine this definition by tracking the advocacy for participation (as understood above) within the fields of foresight and futures studies, in which citizen participation has been encouraged across decades for the development of societal-scale, long-term visions and plans. Some of the early ground work for this term includes Robert Jungk's famously original "future workshop" model developed in the 1970s [33], the Anticipatory Democracy movement [5], foundational papers of the Institute for the Future [14], early technological foresight work in the 1980s [42] participatory process to map and define "systems of provision" [77], and foresight at the societal scale $[10,68]$. Much of the recent development in defining participatory foresight is well documented in [51], though we would contend that the goal of participatory foresight is not to better predict or anticipate the future, but to strengthen peoples capacity to recognize and embrace uncertainty while collectively shaping a preferable vision of the future.

Participatory foresight methods vary considerably in the specific tools that they employ, but are unified by a common attractor-fostering inclusivity in the creation of narratives and images of the future that reflect the diversity and complexity of society. We address three methodological approaches to participatory foresight that engage the critical and creative faculties of communities and their members. As one approach, citizen visioning is understood as a method through which citizens develop a shared vision of their preferred future as a community. One method for the visioning could be to ask the participants to imagine routine elements of an optimal daily life in a future time [19, 29]. This method might be utilized within a foresight project's broader research design as an opening element [82], or as a process with distinct expected outputs [7, 8, 45, 85].

In addition, the futures dialogue method is a flexible framework for structuring future-oriented discussions between stakeholder groups [3, 15], and is often utilized when issues must be considered at multiple scales of governance $[17,26,66]$. Its primary methodological function is to broaden the scope of perspectives informing a particular set of decisions by encouraging stakeholders to develop multiple, often contentious, desirable futures. Additionally, futures dialogues present opportunities for multi-lateral learning and awareness raising on issues like local concerns, policy goals, and sociotechnical trends [80].

A third methodological approach, narrative generation, is elementary within foresight and futures studies [27, 28, 47] with a particular resurgence in interest beginning in the 2010s as transdisciplinarity between design and foresight became more popular [22, 40, 46, 61]. Of particular 
note with this methodological approach, narratives and storytelling have been particularly linked to human cognitive processes with regard to learning and sense-making [47], along with simulation of future possibilities to create actionable convictions under radical uncertainty [73].

Depending on the scale and ambitions of the project, public participation can range from tens of participants $[4,12]$ to thousands [69], and despite a historical record that reaches back decades, it remains an under-utilized methodological format [64]. With regard to agendasetting and planning exercises, participatory foresight has been slowly gaining momentum as an approach $[16,25,38,51,65,71,83]$. A recent analysis of results from participatory visioning projects speaks to their ability to generate meaningful consensus around specific topics [57] - the basis of which could be mission writing, goal setting, or policies planning.

In our view, these participatory processes, and the artefacts they produce as outputs (alternative futures, personas, and narrative scenarios, etc.), define a field of information that lends itself to outlining both a policy agenda and the actors prepared to contribute to mission-oriented innovation systems. Key outputs from participatory foresight methods can include multiple images of a desirable future, and personalized narratives that animate the future-demonstrating the actors, organizations, technologies, and social political trends that shape daily life. The desirable visions can vary in the scope of issues that they address, the communities they attempt to speak for, and the perspectives taken into account [6]. They can be the basis of motivating narratives capable of compelling individual and collective actions [21]. Additional outputs of participatory processes can include prioritization of public needs, stakeholder analysis, rich cultural and contextual information, and a brief history of past agendas' successes and failures [2].

Recent work in the conceptualization and study of innovation systems has given more significant consideration to inclusivity and the social dimension of innovation $[18,53,65,67,80]$. Through a more reflexive innovation framework [20, 41, 78, 81], these systems can acknowledge the contributions of new institutions and realize the benefits of heterogeneous actor groups [20, 78]. By incorporating reflexivity into innovation systems, and thereby enabling a wider spectrum of social actors to influence the direction of change, reflexive innovation processes set the tone for normative re-orientation introduce directionality into the search process $[41,70,79,84]$. However, the capacity to influence the direction of change only underscores the importance of defining the destination a shared vision of a socio-technological future reflective of the common values and goals of involved actor groups. In an examination of future prospects for innovation systems at large, there is strong support for the proposal that reflexive innovation frameworks be introduced as a salve for the "more is better" ethos that drives much private sector innovation activity $[37,39]$. At the same time, there is now a widely shared understanding that challenge led missions need certain new qualities in order to effectively drive the transformations required. Recent research [11] is converging around aspects like:

Socio-technical: Aligning social and technological innovation

- Systemic: Focusing on system change rather than on individual elements alone

- Diffusion oriented: Focusing not only on the upstream phases of innovation but also on the integration of solutions into real world conditions

- Transition-oriented: Envisaging system transition rather than only incremental trajectories

- Glocal: Mobilizing and aligning a diverse range of local solutions to address grand challenges on a global level

- Transdisciplinary: Joint research and innovation across disciplines

- Participatory: Involving actors with diverse perspectives such as users and providers as well as stakeholders in joint learning processes

We propose that the inclusion of bottom-up participatory foresight activities, as one element of reflexive innovation, can both provide a more specific futureorientation to innovation processes, and by so doing, increase the efficiency and efficacy of innovation systems. Furthermore, participatory foresight activities can give clarity and focus to "mission-oriented" goals within the context of societal expectations and needs and finally contribute to achieve the required qualities of effective innovation policy missions.

To support this position, we present the results from two recent projects that incorporated bottom-up participatory foresight methods to engage public discourse with macro-scale system transformation: CIMULACT ${ }^{3}$ which approached the transition to sustainable societies using citizen visioning, and BioKompass ${ }^{4}$ employing future-oriented citizen dialogs coupled with participatory narrative generation to build a multi-stakeholder understanding of the "bioeconomy" and thereby foster transformation toward it. The CIMULACT and BioKompass projects were chosen as they represent two recent examples of innovative and ambitious participatory foresight projects. CIMULACT was selected because of its broad

\footnotetext{
${ }^{3}$ http://www.cimulact.eu/

${ }^{4}$ https://www.isi.fraunhofer.de/en/competence-center/foresight/ projekte/BIOKompass.html
} 
scope of participation from European nations, the projects equally broad goal of discovering different conceptualizations of "sustainability," and our past work in comparing citizen and expert contributions to the project's outputs $[24,58]$. The EU wide scope of the CIMULACT project, allows for an examination for generalized qualities of citizen contributions that reach across language, culture, and socio-political differences. The BioKompass project was selected due to its multi-phase citizen engagement whose products shaped the public facing exhibit at the Senckenberg Naturmuseum, and our team's involvement with various components of the project. The BioKompass allows for a longitudinal examination of citizen contributions, and an examination of the effect that transmedia and immersive experiences might have on those contributions. As active participants, our analysis benefits from first-hand observational knowledge-enabling a closer examination and articulation of the process and products as presented here.

While each project operated at different scales of engagement, participation, and scope of content, we think that the results demonstrate the participatory foresight's general utility in discovering societal needs and defining missions and goals in participatory processes that include one or more future-oriented activities. This substantiates our claims that such processes can activate a more fluid and reflexive innovation system as prerequisite for system transformations. After presenting the two projects, and in particular the citizen-generated artefacts they produced, we assess the nature and legitimacy of their contribution, outline possible impact pathways, and finally deduct five aspects of added value from citizens involvement to reflexive innovation systems and their normative orientation.

\section{CIMULACT-Citizen and Multi-Actor Consultation on Horizon 2020}

The CIMULACT project, funded by the EU H2020 programme, engaged citizens, along with a variety of other actors, in contributing to a re-definition of the European Research and Innovation agenda and thereby makes it relevant and accountable to society. CIMULACT was cited in the latest report on Governing Missions in the European Union [44] as it provides an excellent case study in the pathway of local citizen visioning processes as vehicles for carrying social hopes and aspirations into the policy-making and governance institutions in Europe.

The project did so by having more than 1000 citizens in 30 countries in Europe to formulate their visions for desirable sustainable futures, to debate and develop those visions with other actors, and to transform them into recommendations for future research and innovation policies and topics. The project had 29 European consortium members from different organizations working in the fields of technology assessment, science dissemination, innovation, research and consulting, coordinated by the Danish Board of Technology Foundation. The citizen visioning process was ambitious in both scale and scope [32] by gathering over 950 individual vision statements in face-to-face meetings that followed a unified method while remaining adaptable to local cultural practices. Emergent from these individual vision statements, nearly two hundred co-created citizen visions were arguably one of the project's most valuable assets, as they reflect the initial stages of community dialogue and negotiation that are needed to outline and refine a collective vision. To date, CIMULACT remains one of the largest formal visioning projects within the $\mathrm{EU}$ [8]. It can be differentiated from other large-scale participatory foresight projects like VOICES [7] and CIVISTI [69] in its level of documentation, and in the processes by which the visions were taken into policy discussions regarding Horizon 2020 (FP8) and Horizon Europe (FP9). Citizen visions were subjected to two additional phases of future dialogue and expert workshops with policy makers, in order to prepare them for presentation to policy makers and to derive policy recommendations. Despite certain cultural and contextual nuances, major common elements of the visions served to consolidate the data set into a number of policy recommendation areas. The main themes of these policy recommendations were found to be highly consistent with the visions themselves when compared with results from topic modeling testing on the visions [57].

In previous comparative research regarding the policy recommendations these visions produced, several citizen contributions were highlighted as highly novel and distinct from "expert" views [24,59] (see Table 1). This is not to say that citizen-generated "research topics" are by themselves unique, but that futureoriented participatory processes with high levels of citizen engagement will emphasize and formulate perspectives and concepts differently when compared to foresight activities that have minimal non-expert input channels. This aspect of novelty is derived from citizen expertise in the activities of lived daily life, and their lived experience as interactors with a large number of social and technical systems. Given the emphasis that CIMULACT placed on the need for localized knowledge as an input to contextually sensitive solution finding, we suggest that these areas-little mentioned via expert-based foresight, and seemingly unaddressed in innovation policy at the time-highlight the types of contributions that direct citizen engagement and structured participatory foresight can provide. 
Table 1 CIMULACT research topics in which contributions by citizens were viewed as novel with respect to expert based inputs on the research areas. For more detail on these comparative differences please refer to (Gudowsky and Rosa 2019)

CIMULACT Citizen-Based Research Topics with distinct perspectives not covered by expert based Foresight studies

Access to equal and holistic health services and resources for all citizens

Research should define the state of the art of the healthcare system in the different European countries in order to promote an equal distribution of resources and knowledge with a Pan-European dimension.

\section{Balanced work-life model}

Research should rethink the definition of "work" and develop approaches that permit to recognize and reward as "work" all different kinds of human activities including socially valuable daily life activities such as domestic work, childcare, caring for the elderly and social work.

\section{Finding a balance in a fast-paced life}

Research and innovation activities should explore ways to support citizens to manage their daily lives in a balanced way by valuing relationships, taking breaks and creating opportunities for recreation.

\section{Promoting well-being through relating environments}

Research should develop empowering and supportive physical and virtual environments for cooperating and learning at the individual, workplace, and community level

\section{(Business)Models for balancing time}

Experimenting with or setting up work-life balance pilot programmes

\section{Evolving food Cultures in big cities}

Research should explore how cities could cater to increasingly diverse food cultures in a sustainable manner

\section{Collective Transportation Options}

Applied research should be developed on transport systems: less based on new infrastructures; less top-down organized and more communitybased, self-organized; capable to enable socialization; based on flexible units.

\section{Basic Universal Income}

Theoretical and empirical research should be developed to investigate ways to implement a BUI.

\section{Debating Alternative Economic Models}

Community Support Actions should design a multi-actor approach to foster a dialogue about experiences with available alternative economic models, with the aim of building a common knowledge base, dissemination to and engagement of all relevant stakeholders in co-creation activities, integrating and adapting models for regional/local context, developing strategies for policy implementation

\section{Relocalizing Investment and Finance}

The current financial sector needs reformation to foster sustainability and well-being. Research should explore how to foster this transition

\section{Educational Ecosystem}

Research should investigate how systematic learning could be used as driver for local innovation and development.

\section{Design Thinking and Life skills}

The research should investigate the power of design inquiry, thinking \& doing / as a mean to foster creativity and innovation and boost learners' abilities to think "out of the box" (set and solve the so called wicked or "ill-de-fined" problems)

The CIMULACT citizen-based visions received considerable attention from researchers and practitioners in innovation policy and participatory governance and were also mentioned in the introductory section of the
Horizon 2020 programme. ${ }^{5}$ While it is difficult to identify the project's direct impact on the actual Horizon 2020 priorities and calls, the visions were discussed with European Commission staff working on the program development, were mostly well-received, and in all likelihood had some influence on the overall outline of ensuing calls.

\section{BioKompass-Communication and Participation Engagement for Societal Transformation toward the Bioeconomy}

The BioKompass project, funded by the German Federal Ministry of Education and Research (BMBF), was initiated to open up both a civic dialog and public awareness building process concerning the expected bioeconomy transition, defined as a shift away from fossil resources toward bio-based resources, products and processes, and its potential impacts on daily life for German citizens. The foresight process has involved technology experts, students, and diverse citizen groups to develop alternative scenarios for the bioeconomy in the year 2040 . These scenarios have been used subsequently in public future dialogs on how life will change in a bioeconomy, in educational curriculum, and are core elements of the public exhibition on bioeconomy "Shaping our futureHow do we want to live?" at the Senckenberg Naturmuseum in Frankfurt, Germany.

Citizen participation was embedded across the phases of the foresight process to integrate diverse voices into the development of alternative futures for a national bioeconomy. First, a stakeholder mapping was carried out to identify relevant actors, today and in the future, in different roles in the innovation system. Then the research team developed a future dialog with more than 60 citizens and experts with the aim to discuss with the participants how bioeconomy might affect everyday life, with regard to specific "fields of need" (e.g., mobility, housing, consumption, food, work, etc.) along the lines of previous "needs areas" work [74, 77]. This initial meeting highlighted an opportunity for mutual awareness raising-with citizens learning multiple viewpoints on what the Bioeconomy could become, and stakeholder groups becoming aware of citizens' prioritization of their daily life activities in the consideration of technologies

${ }_{5}$ https://ec.europa.eu/research/participants/data/ref/h2020/wp/2018-2 020/main/h2020-wp1820-intro_en.pdf page 48 : “The consultation also extended to the existing thematic groupings and networks like European Technology Platforms, European Innovation Partnerships, Public-Public and Public-Private Partnerships or Joint Programming Initiatives, as well as the Committee of the Regions, European Agencies (e.g., European Medicines Agency, FRONTEX, EUROPOL) and international bodies like the OECD. The work of specific expert groups (e.g., High Level Group on European Open Science Cloud), the results of FP projects like CIMULACT29enabling direct interaction with citizens, studies and conferences/workshops reflecting stakeholder views were also integrated in the consultation process." 
or policies of the Bioeconomy. Building on this process then, and the need for reflexive activities to shape emergent stakeholder perspectives, alternative scenarios were co-developed using citizen inputs, stakeholder positions, and trend research.

At a second civic dialog with more than 50 participants, the scenarios were discussed and enriched using a method of co-creative narrative generation [35]. The data collected during these dialogs identified critical factors shaping the alternative development pathways for the Bioeconomy, while narratives provided links to physical artefacts used in the Evolving Lab, and as exhibition content at the museum. Through the co-creation of persona-based stories focused on the daily-life behaviors of inhabitants within each alternative, citizens were able to articulate modes of social change, including shifts in value and ethical assessments that were central to the shape of each alternative future.

These narratives communicate the divergent scenarios by demonstrating transformations in the everyday life settings of various target groups, and thus make the broader scenarios more accessible for continuous, widespread citizen engagement. The scenarios and the results of these future dialogs, e.g., the co-created narratives, formed the basis for subsequent dissemination via teaching material and the interactive exhibition, accompanied by a virtual tour on their website ${ }^{6}$ and an app with educational content to be used in the museum. The exhibition now provides artefacts, statistics, as well as explanations around three of the four alternative scenarios of the Bioeconomy and demonstrates how differently the bioeconomy can be understood, designed, and developed and above all, how individual consumption patterns and life-styles can influence it and vice versa will be influenced by it.

Each scenario addresses different development trajectories for topics central to any future bioeconomic development, and their impacts on policy spheres, technological development, economic structures, individual practices, and quality of life. Though the conversation was restricted to developments within the German context, the critical topics selected were (a) consumer behavior, (b) origins of biobased raw materials, (c) origin of food products, (d) primary use of biobased raw materials, (e) energy mix of fossil and bio-based raw materials, (f) quantitative and qualitative land use, (g) alternative economic models, and (h) approaches to circular economy systems.

The integration of each topic's development pathways into the respective narratives encouraged focused speculative dialogs as to the different types of lifestyles that alternative bioeconomies would enable. As these conversations proceeded, details for each narrative

\footnotetext{
${ }^{6} \mathrm{https://senckenberg.livelinks.adornis.de/}$
}

became more concrete, and the relationship between governing policies and stakeholder capabilities became more tangible. This, we argue, is precisely the type of emergent bilateral awareness-raising that participatory foresight processes can lend to the coming 'mission' definition and goal-setting phase the next framework program requires (Table 2).

The BioKompass scenarios and narratives were not only developed in a participatory way but also discussed with numerous groups of actors. For example, during an evening event with over 50 participants at a science festival, they were evaluated with regard to their various positive aspects. The BioKompass results triggered very intense discussions among lay people, students, and experts from industry. Visitors to the museum were asked to write down conclusions for their own private actions, and the feedback shows a vivid involvement of the visitors. A major focus of the BioKompass scenarios and narratives were pupils and teachers. Based on the BioKompass results, students developed not only two different board games but also outlined school lessons on bio-economy. These will now be tested in a school over the next few months. The complex multiperspective futures of the BioKompass do not provide simple conclusions that can be easily implemented. As a consequence, despite a great deal of interest in the narratives, it is necessary to focus on effects on everyday life and to develop targeted formats for lay people to win

Table 2 The co-creation workshop conducted with citizens and stakeholder groups produced (a) alternative futures scenarios,

(b) personalized narratives within each scenario, and (c) secondary artefacts that emerged from (a) and (b)

BioKompass products co-created by experts and citizens with perspectives not covered by expert-based foresight studies

Four scenarios, co-developed with citizens:

Scenario 1-Rising high with high-tech bioeconomy

Scenario 2-Bioeconomy through ecologically conscious lifestyle

Scenario 3-The European bioeconomy bubble

Scenario 4-"Sustainable bioeconomy —Made in Germany"

Eight narrative driven personas, co-developed with citizens to examine daily life in each scenario:

Scenario 1-Future story of Beate: Hightech savvy, environmentally conscious and self-sufficient; future story of Barbara: freelance online teacher and forest lover

Scenario 2-Future story of Oda: Environmentally conscious and thrifty by conviction; Future story of Oskar: Successful organic farmer Scenario 3-Future story of Lili: Engaged in Sharing and Do-it-yourself; Future Story of Luis: vegetables in the backyard or in-vitro-meat?

Scenario 4-Future story of Taira: Living in a self-providing alternative community; Future Story of Tina: organic agriculture - complex and with autonomous machines

\section{Artefacts for information and communication about the future} challenges:

Exhibits co-designed with students from each scenario and presented in the interactive exhibition in the natural history museum; Student-

developed, future-oriented "serious game" as medium for interactive outreach and awareness raising; Information boards developed by students for the museum and science festivals 
them over to an intensive involvement with diverse future perspectives.

\section{Analysis}

Participatory foresight methods help stakeholders and actors to engage in long-term critical and creative thinking, often generating a number of different products in the process. By examining the different processes and outputs from CIMULACT and BioKompass, we aim to articulate a framework for assessing and accounting for citizen contributions as potential input channels into policy discussion and increasing the reflexivity of policy formulation processes. We have organized this analysis with respect to the primary research questions we believe to be relevant to the construction of such a framework.

- What are the specific qualities of citizen-based visions and artefacts?

Despite the differences in artefact formats, and the actor groups they were designed to serve, both sets of artefacts succeed in creating a communication bridge between the citizen perspectives of local, everyday experience, and long-term policy goals often with a global perspective. In both cases, this bridging is much richer than conventional "science communication" as the citizen perspective stems from actual discourses and incorporates "real voices" rather than having been imagined by scientists or communication experts (Table 3 ).

In previous research $[24,59]$ we have investigated the difference between the citizen-based and expert-based suggestions for research and innovation priorities for the

Table 3 From both the CIMULACT and BioKompass projects, citizen contributions served as primary material for one or more products of participator foresight processes

Citizen-based Contributions from Participatory Foresight Processes in CIMULACT and BioKompass

\begin{tabular}{|c|c|}
\hline $\begin{array}{l}\text { CIMULACT Foresight Process } \\
\text { Artefacts }\end{array}$ & $\begin{array}{l}\text { BioKompass Foresight Process } \\
\text { Artefacts }\end{array}$ \\
\hline $\begin{array}{l}\text { Citizen generated visions of a } \\
\text { sustainable society }\end{array}$ & $\begin{array}{l}\text { Scenarios co-developed with } \\
\text { citizens }\end{array}$ \\
\hline $\begin{array}{l}\text { Research Topic Areas co-developed } \\
\text { by citizens and experts }\end{array}$ & $\begin{array}{l}\text { Narrative Personas co-developed } \\
\text { with citizens to examine daily life } \\
\text { in each scenario }\end{array}$ \\
\hline \multirow[t]{3}{*}{$\begin{array}{l}\text { Finalized Horizon } 2020 \text { topic } \\
\text { suggestions and policy } \\
\text { recommendations. }\end{array}$} & $\begin{array}{l}\text { Imagery and designs for futures } \\
\text { artefacts from each scenario } \\
\text { presented in museum exhibition. }\end{array}$ \\
\hline & $\begin{array}{l}\text { Student-developed, future-oriented } \\
\text { 'serious game' as medium for inter- } \\
\text { active outreach and awareness } \\
\text { raising }\end{array}$ \\
\hline & $\begin{array}{l}\text { Information boards developed by } \\
\text { students for public exhibition. }\end{array}$ \\
\hline
\end{tabular}

case of CIMULACT. The analysis showed that the citizen-based priorities did not provide entirely different topics than the experts, but offer a different way of emphasizing the topics and approaches that they imagined would work within their lived experiences. Our observations, later confirmed through close comparative reading [59], noted a substantial difference in how citizens framed these topics, and used this framing to provide novel insights, in the following ways:

1. Citizen inputs tend to be holistic: We have observed that citizen thinking tends to cut across institutional silos, and in effect be transdisciplinary in its search of defining challenges and proposing solutions.

2. Citizen visions reach across scales: They are deeply embedded in the socio-cultural context and daily life experience, while at the same time reaching out to ambitious global and long-term goals.

3. Citizen thinking opens up new perspectives as it is unencumbered by policy restrictions that are deeply engrained in expert and policy maker discourse. Thereby, it serves to counteract groupthink and cognitive biases hampering open and creative thinking.

One example that illustrates all three aspects is the strong emphasis on new forms of education-a theme that emerged consistently across the nearly 200 cocreated, citizen visions. This was considered both an important topic in its own right (e.g., "Design thinking and like skills"), and was often integrated into citizen vision on other topics such as food, mobility, environment, and health [32]. As education is not a priority line in Horizon 2020, there were limited options to feed in these aspects into the R\&I agenda. However, the overall impression from the CIMULACT visions led to a heated discussion among policy makers on the possibility of restructuring Horizon 2020 to accommodate education related research. Perhaps it is here that citizen visions can be their most provocative-by highlighting gaps in existing structures, and creating opportunities for policy-level discussions that can include citizen-based priorities and effect structural change.

Indeed our observations within the citizen and expert exchanges of the BioKompass project confirm that there may exist fundamental differences between the mode of prioritization for citizens and that used by policy experts. In examining the BioKompass scenarios, we find more evidence citizen creative contributions can reach across silo policy spheres-for example blending bioeconomy technologies into a rich set of daily life aspects, or reflecting on local cultural contexts with respect to global sustainability and health goals. While the BioKompass 
project remains ongoing, and its impact assessment is not yet completed, we are curious if the results will be similar-that participatory processes result in difficult to measure direct effects on policy, and yet their contributions provide an important critical lens on the structures and institutions through which policy is enacted. If this turns out to be the case, then we have further evidence supporting greater participatory processes, and to continue experimentation in governance design that can address the critical question:

- What is the added value of these qualities for establishing mission-oriented policy?

The observations above imply that the added value from bottom-up participatory processes is not so much the content of the suggested priorities but the unique framing of challenge areas provided by the citizens' perspective. It is here where we see an alignment with the requirements of mission-oriented policy literature outlined above:

- Socio-technical: Aligning social and technological innovation

- Systemic: Focusing on system change rather than on individual elements alone

- Diffusion oriented: Focusing not only on the upstream phases of innovation but also on the integration of solutions into real world conditions

- Transition-oriented: Envisaging system transition rather than only incremental trajectories

- Glocal: Mobilizing and aligning a diverse range of local solutions to address grand challenges on a global level

- Transdisciplinary: Joint research and innovation across disciplines

- Participatory: Involving actors with diverse perspectives such as users and providers as well as stakeholders in joint learning processes

When we compare these key aspects with our observed characteristics of citizen-based perspectives in futureoriented activities, a strong correspondence emerges with particularly relevant implications. These observed characteristics of citizen contribution include:

- Citizen-focused pluralism: By utilizing the future as a space of possibility that can be occupied by divergent demands, bottom-up participatory foresight can bolster broad representation of localized conditions and expectations within the agenda setting process, and foster inclusion of the multitude of "bottom-up" perspectives that might otherwise be silenced.
- Diffusion-orientation: By bringing citizens and stakeholders into a productive dialog to voice respective needs, and to define priorities and goals that serve to form "missions," participatory foresight engenders greater public purchase in the long-term, macro-scale goals by bridging 'missions' and community-level demands. These processes enlighten innovation teams regarding the localized needs, challenges, and aspirations that RDI can address, and often provide insights into the societal narratives that drive buy-in and adoption and thus ultimately speed up diffusion.

- Systemic scope: Citizen perspectives have the potential to introduce "holistic" and "silo bridging" elements demanded by "transformative" missionoriented innovation policy as it emerges from a direct experience of daily life problems that is not filtered through the lens of policy sectors. Indeed, citizen contributions are often unencumbered by policy silos, and connect the importance of multiple sectors collaborating to the addressing of local needs.

- Socio-technical/transdisciplinary: Bottom-up citizen contributions bring in the social aspects required for socio-technical transitions and fosters the social innovation aspect even within technology arenas. In addition, the participatory processes mobilize implicit, everyday-life knowledge that is not usually captured in expert-based processes, and is therefore truly transdisciplinary by nature.

- Textured perspectives: Individual contributions tend to provide granular detail when dissecting challenges within their current daily routines, and are thus able to provide a similar level of detail and complexity when generating artefacts, be it imagining the lived experience of a future scenario, or creating a deeply personal object for a scenario persona. This enables the artefacts to attract a deeper mode of critical engagement with a scenario's content and implications for potentially global, societal phenomena (traffic, waste, etc.).

To explore in a bit more tangible manner how this added value could actually be unlocked within a policy agenda context, we now sketch a possible impact routes for the type of findings emerging from bottom-up participatory projects like CIMULACT and BioKompass.

- What are potential inroads for impact of citizenbased foresight artefacts?

Given that participatory foresight processes generate a variety of outputs and artefacts that communicate community desires and values, opinions on technological 
developments, and social behaviors, the question remains how to integrate topics central to those visions within RDI agendas. We submit that the problem remains wicked, but that the utilization of participatory foresight can offer a fundamental advancement in the translation of citizen visions to shared, holistic "missions" through co-creative activities centered on longer-term time horizons. Our discussion is an observation-based reflection on how these processes, and the artefacts they produce, can facilitate "bottom-up" mission-defining processes, goal-setting for innovation policy planning, and can thus be of fundamental use within a reflexive innovation system.

First, let us consider how results such as those produced by CIMULACT-citizen generated research topics that contained many novel components, suggestions, and perspectives when compared to expert contributions to a similar topic-can be utilized to jointly develop missions. Referring again to the topics in Table 1, we will consider the research topic "Finding Balance in a Fast Paced Life" as an input into the mission finding process. What might be achieved if this topic, and others like it, were the focal point for a future-oriented, multi-actor dialog? A forum designed to (a) define a mission that addresses this need, (b) discuss concrete policy goals between regional leaders (mayors, city councils, etc.), business interests (SME leaders, entrepreneurs, etc.), policy-makers, and (c) guarantee that citizens and residents who fall outside of these categories can shape those policies with their diverse perspectives from lived experience in a presumably unbalanced, and likely unhealthy and unsustainable, society.

With this topic as their starting point, the members of different actor groups can share their thoughts on what constitutes a balanced life (amount of free time, community activities, etc.), what values propel this issue up the local priority list (family, justice, etc.), and actor relationships that effect this balance (employer/-ee, business/ consumer, etc.). As the localized inputs regarding this topic begin to accumulate, a two part dialog can proceed. Firstly, a look at ideal states for each of the stakeholder groups can be negotiated regarding the concept of "balanced-life." Such a definition is essential to the ultimate framing of the mission-statement for demand-oriented innovation policy. The second phase then attempts to "future proof" this definition, by examining the dynamics and stability of values, actors, technologies, and social relationships over a longer time horizon.

Through this dual-layered approach, citizen dialogue facilitates a co-discovery of the various forces in play with regard to a research area in both the short and long term, and allows for a mission statement to be defined that accommodates all major groups. In this example, such statements around "balance in a fast-paced life" might include the hypothetical examples: (1) ending financial instability for all residents, (2) providing all citizens with recognition for their formal and informal contributions to a society, (3) unraveling social competitions that provoke or incentivize unhealthy behavior, (4) instituting regional happiness index with direct influence on all major stakeholder group "daily-life" operations, (5) zero-tolerance for work induced stress, or (6) guaranteed right to self-care and development. Statements such as these do not offer solutions so much as outline new perspectives on the problem itself-new formulations of old challenges, or novel challenges that current policy cannot account for.

We might further consider how narrative generation can facilitate in bringing lofty, but ambiguous, goals back within the sphere of everyday life. In so doing, these stories can utilize various concepts (technological, legal, organizational, etc.) to illustrate how a future imaginary might impact the life choices and daily routines of a vibrant citizenry. This was precisely the aim of the BioKompass narratives - written to engage with a public who may have little foreknowledge of the bioeconomy and its implications. With each narrative emphasizing different aspects of the alternative pathways defined through futures dialogs, they serve as a vehicle for communicating ambiguous future assumptions into the cognitive apparatus that creates personal meaning from simulated experience. For stakeholders in a reflexive innovation system, these narrative artefacts provide examples, however hypothetical, about user motivations (designers), system integrations (engineers), social incentives (policy-makers), new products and services (industrial sectors), and even new cultural behaviors (CSOs).

To demonstrate how this works, we might look more closely at different statements from just one of the eight BioKompass narratives:

Two years ago, with a lot of luck, she got her hands on the mini apartment in the $\mathrm{CO}_{2}$-neutral residential complex and is thus one of the pioneers who live in a wooden zero-eco footprint building in the city. After breakfast, she rinses off, quickly packs the waste into the bioplastics bin and puts it into her bicycle to dispose of it in the central bio-waste bin on the way. She takes the children to the kindergarten and discusses with the educators their sons' meal plan for the week. Both, like most of the children here, are fed vegetarian.

Within short portion of the narrative, we find motivations in the phrases like "with a lot of luck"-entailing that effort was expended for the protagonist to exercise her living choice-a zero-eco footprint building. This 
housing concept, while not novel, has become more widespread in this future-an integral component of the larger social experiment: $\mathrm{CO}_{2}$-neutral residential complexes. The existence of such complexes further hints at overlapping systems-central bio-waste, bioplastics for food, and integrated education systems. These are just some of the points at which a reflexive innovation system could engage with a possible and desirable future as articulated through citizen-based dialog and co-created stories. Some elements of this narrative would be appealing to city planners, others to housing design and engineering teams, and others yet to societal policy-makers.

If such statements were to emerge as products of a future-oriented, multi-actor, citizen-driven process, how might they be useful in a challenge led innovation policy context? In seeking to unlock the added value of citizen perspectives for mission development outlined above, it is essential to first engage with diffuse ideas of desirable futures that permeate one or more locales, second, address ambiguities that emerge and their variety according to localized socio-political factors, and thirdly, feed this diversity of needs into the mission generation process without compromising the localized trust that has been generated through participatory processes. This three-step process must then become a continuous effort so as to both monitor progress as observed by citizens and to accommodate, and respond to, changing needs.

\section{Discussion}

We have outlined what could be the added value of citizen based participatory foresight processes for establishing mission-oriented policy priorities and then embarked on envisioning impact pathways in the form of processes that would actually unlock these potential benefits. Our current reality, however, shows a different picture. The translation of these foresight process outputs into policy recommendations is a particularly strong challenge, and many well-designed participatory processes end up with little or no impact in the policy realm. Policy makers use a focused, solution-oriented language, while citizens expectations and demand expressions sometimes tend to downplay detailed solutions and focus more on holistic, qualitative social changes [58]. In part, this might be why the "mission" language is so appealing-it attempts to bridge this divide by allowing the overarching mission to broadly appeal to citizen concerns, while giving the policy makers a filter through which to set concrete goals and thus set an agenda into motion. However, as bridginglanguage decisions remain tethered to traditional, centralized, and hierarchical systems on which governing institutions are built, the discrepancy remains between expectation of citizens and policy-makers with regard to both the timing and type of innovation outputs [24].
Such discrepancies in citizen expectations and expert recommendations have been observed with regards to the ambiguous term "smart city." On the one hand, projects and funding lines utilizing this term have been linked to phenomenon of citizen exclusion-in which, despite repeated calls by stakeholders for the opposite [13], citizen demands are subsumed by the technocratic understanding of what a "smart city" entails. This holds in contrast to a number of participatory foresight processes, focused on the citizen expectations of a "smart city," that have demonstrated positive results for urban visioning $[12,50,56]$. Such phenomena strengthen our claim that participatory foresight processes be integrated across the entirety of large-scale, long-term projects likely to emerge from the EU's mission-oriented approach, and the innovation systems that will be needed to address them.

Furthermore, there is limited evidence regarding how artefacts from participatory foresight (visions, narratives, design objects, etc.) are utilized by reflexive innovation systems. In CIMULACT, as citizen visions moved from their initial creation toward policy recommendations at later stages of the project, the vision statements were run through a number of language intensive processes (translation, comparison, categorization, and combination) by "expert" groups. What was lost and gained from such an approach requires further assessment, particularly as it pertains to the shaping of detailed missions that can clearly enunciate to engineers, planners, policymakers, strategists, and the general citizenry. Could such a narrative also be created to both wrap a world around the previous mission statements from our thought experiment, and run a thread of individual experience through that world? We might conceptualize such processes as instituted components of reflexive innovation systems-clarifying the phase transition from "bottomup" ideation to "systems-based" solutioning.

By establishing some guidelines by which citizensourced needs, aspirations, and opinions can be better integrated into ongoing mission-oriented innovation processes, higher order governing entities can improve both funding-policy and its products [52]. Such an attempt could build on the body of research relating to the understanding of effects and impacts of deliberative processes and transdisciplinary research [60] as well as more general typologies of impact pathways [31]. In a way, the final policy recommendations of the CIMULACT project reflected the storytelling approach embedded in its citizen visioning phase. Though the focus on such singular experience was later softened, we assert there remains ample evidence that CIMULACT, and other participatory foresight exercises, would provide the same nuanced narratives if designed to do so. If such narratives can provoke adoption by various components of reflexive innovation as demonstrated above, then 
future citizen-based or multi-actor projects become prime candidates for testing the emergence of innovation-focused social narratives.

When we consider the position of policy-makers charged with confronting wicked problems using limited policy instruments, and the foreknowledge that no singular "solution" exists, we believe that the missionoriented approach is absolutely appropriate. Just as the Apollo missions distributed $R \& D$ funding across a huge number of public and private actors, the missionoriented approach suggests a similar tack. The purpose is to achieve the mission goal, however lofty and "impossible" it may seem, not through competition-oriented, prioritization schema for pre-selecting the most costeffective proposal, but by unfolding the problem and approaching it from all vectors at the inception of agenda setting processes. These missions demand more than technical proficiency and innovation alone, they require, and often inspire, a more fundamental transition of social systems in their entirety. This is not to say that social systems will become unrecognizable, merely that achieving mission goals will both foster and compel changes across the spectrum of societal activities. Seen in this light, social aspects of systems take on a new importance, and citizens, as authorities on the living of daily life, bring a vital expertise to the table. In the above example taken from BioKompass, we see that the zeroemissions residency is not a solution unto itself; it is one component of a daily life touched by ecologically focused solutions within the Bioeconomy. The macro requires the micro, just like in the space shuttle, in order for the mission to be achieved, and in so doing, placing humanity within a new paradigm of existence. In 1969, we became an extra-terrestrial species. Perhaps, operating under a mission orientation to innovation for broad systemic change, we might by 2069 redefine ourselves as a terrestrial species. Indeed, it seems that if we are to remain a species at all, such change might be required.

\section{Conclusions}

We have made the case for considering citizen-based, participatory, future-oriented processes as one valuable element in constructing high-level missions from the diverse cultures of the EU citizenry, but more work remains to be done. The observed qualities of citizen contributions derived from participatory foresight processes, as presented here, is not likely comprehensive, and requires further testing and use cases in future research. We will utilize this framework in future projects to test its validity, but welcome others to advance the analysis of citizen contributions by adapting this list of qualities to their own assessments. Additionally, reflexive innovation demands some technical skills be present within the solutioning conversation, but are not a prerequisite for success, speed, or scalability. Such innovation requires time and process, both of which can be seen as worthwhile investments for building localized innovation ecologies and reaffirming support and trust from citizens. Participatory foresight does offer opportunities to enhance reflexivity, if stakeholder dialogue can be increasingly diversified, and citizens are enabled with greater agency-within a co-creation process of future-oriented artefacts as a starting point.

With the upcoming launch of the $9^{\text {th }}$ EU Framework Programme for R\&I, and the rhetorical devices being deployed as guides to its development, it seems that "mission-oriented" policy has much to gain from citizen involvement. Our evidence suggests that participatory foresight processes are capable of engendering the type of "bottom-up" engagement that can contribute to creating ambitious and powerful societal "missions" across diverse regions and locales. In particular, we have highlighted the transdisciplinary, holistic, and systemic nature of the citizens input as well as the embeddedness into local cultural and social context-characteristics that are widely recognized as key for successful missions. These specific contributions will take different forms depending on the nature and type of mission arena, but to be clear, there is more at stake here than just solutionfinding or "mission accomplished" moments. The opportunity to reinvigorate the social contract, and public trust in governance, is vital to the longer-term goal of maintaining national and international relationships.

To address this aspect of participatory foresight's role in contributing to the development of challenge-led missions for innovation policy, further research is required to better formulate how citizen inputs can be channeled through governance processes to the resultant policies themselves. Projects like CIMULACT, CIVISTI, and VOICES already attest to the efforts that the EU has made to be more inclusive of citizen inputs to policy, but in each case the threads that tied policy ideas to citizen voices were somehow cut. Both CIMULACT and BioKompassdemonstrate the essential need for consistent, multi-lateral dialog to ensure mutual learning across stakeholder groups, and a careful balance between actors and power in reflexive innovation processes. Whereas CIMULACT attempted to "translate up" from citizen visions to policy recommendations, BioKompass clarified the need for constant backand-forth translation activities between citizen concerns regarding their daily lives (also present in CIMULACT) and the policy and industry responses to those concerns. We present these projects for their participatory efforts, but assert that future-oriented citizen engagement projects should emphasize this continuous exchange process in their methodological approaches and research designs. In other words, "bottom-up" exchange may not be enough on its own, but it is a good place to start. 


\section{Acknowledgments}

We would like to acknowledge all of the citizen participants that took part in both CIMULACT and BIOKOMPASS, as they are the real contributors to our futures.

\section{Authors' contributions}

ABR (corresponding author) was involved in CIMULACT and BIOKOMPASS, and was the prime contributor to all segments of this publication. SK and ES were involved in the BIOKOMPASS project and have refined the language concerning innovation systems that utilize foresight processes. PW contributed to the discussion of reflexive innovation systems and the role they might play in R\&l framework program agenda setting processes, and was a team leader for the CIMULACT project. All authors read and approved the final manuscript.

\section{Authors' information}

Aaron B. Rosa: https://www.isi.fraunhofer.de/en/competence-center/ foresight/mitarbeiter/rosa.html

Simone Kimpeler: https:/www.isi.fraunhofer.de/en/competence-center/ foresight/mitarbeiter/kimpeler.html

Elna Schirrmesiter: https://www.isi.fraunhofer.de/en/competence-center/ foresight/mitarbeiter/schirrmeister.html

Philine Warnke: https://www.isi.fraunhofer.de/en/competence-center/ foresight/mitarbeiter/warnke.html

\section{Funding}

Publication funding was contributed by the Fraunhofer GmbH. CIMULACT was a 3-year project funded by the European Commission under Grant Agreement number 665948, starting June 2015 and ending March 2018. BIOKOMPASS is a project funded by the Bundesministerium für Bildung und Forschung (BMBF). Open Access funding enabled and organized by Projekt DEAL.

\section{Availability of data and materials}

The datasets used and/or analysed during the current study are available from the corresponding author on reasonable request.

\section{Declarations}

\section{Ethics approval and consent to participate}

Both BIOKOMPASS and CIMULACT methods and process were conducted under approved ethical considerations for maintaining the physical and mental safety, privacy, and anonymity of the participants. This article maintains upholds that ethical commitment.

\section{Consent for publication}

Not applicable.

\section{Competing interests}

The authors declare that they have no competing interests.

\section{Received: 9 October 2019 Accepted: 11 March 2021}

\section{Published online: 01 April 2021}

\section{References}

1. Arnstein SR (1969) A ladder of citizen participation. J Am Plan Assoc 35: 216-224

2. Bas E, Guillo M (2015) Participatory foresight for social innovation. FLUX-3D method (Forward Looking User Experience), a tool for evaluating innovations. Technol Forecasting Soc Change 101:275-290. https://doi.org/1 0.1016/j.techfore.2015.06.016

3. Bayley C, French S (2008) Designing a participatory process for stakeholder involvement in a societal decision. Group Decision and Negotiation 17(3): 195-210. https://doi.org/10.1007/s10726-007-9076-8

4. Bergez J-E, Carpy-Goulard F, Paradis S, Ridier A (2011) Participatory foresight analysis of the cash crop sector at the regional level. Case study from southwestern France. Reg Environ Change 11(4):951-961. https://doi.org/1 0.1007/s10113-011-0232-y

5. Bezold C (ed) (1978) Anticipatory democracy. Random House, New York

6. Borch K, Dingli SM, Søgaard Jørgensen M (eds) (2013) Participation and interaction in foresight. Dialogue, dissemination and visions / edited by,
Kristian Borch, Sandra M. Dingli, Michael Søgaard Jøorgensen. Edward Elgar, Cheltenham

7. Broerse JEW, van der Ham L, Tielemans Barbara M, Mazzonetto M (2014) Enganging Citizens to Shape EU Research Policy on Urban Waste. Views, Opinions and Ideas of Citizens in Europe. Voices for Responsible Research and Innovation. Brussels. Available online at www.voicesforinnovation.eu

8. CIMULACT (2018) Citizen and multi-actor consultation on horizon 2020. http://www.cimulact.eu, checked on 6/21/2020

9. Cooke B, Kothari U (2001) Participation: The new Tyranny? Zed Books, New York

10. Dahle K (1992) Participatory futures studies: Concepts and realities. Futures Res Q 8:83-92

11. Daimer S, Hufnagl M, Warnke P (2012) Challenge-oriented policy-making and innovation systems theory: reconsidering systemic instruments. Innovation system revisited: Experiences from 40:217-234

12. Eames M, Egmose J (2011) Community foresight for urban sustainability. Insights from the Citizens Science for Sustainability (SuScit) project. Technol Forecasting Soc Change 78(5):769-784. https://doi.org/10.1016/j.techfore.201 0.09 .002

13. Engelbert J, van Zoonen L, Hirzalla F (2019) Excluding citizens from the European smart city. The discourse practices of pursuing and granting smartness. Technol Forecasting Soc Change 142:347-353. https://doi.org/1 0.1016/.t.techfore.2018.08.020

14. Enzer S (1971) IFF Papers. 13:8-25. Menlo Park: Institute for the Future

15. Eriksson E, Arnkil TE (2009) Taking up one's worries. A handbook on early dialogues. National Institute for Health and Welfare. Gummerus Printing. Jyväskylä. Available online at https://www.julkari.fi/handle/10024/80315. Accessed 21 Mar 2021

16. Eriksson EA, Weber KM (2008) Adaptive foresight. Navigating the complex landscape of policy strategies. Technol Forecasting. Soc Change 75(4):462482. https://doi.org/10.1016/.j.techfore.2008.02.006

17. Evans K, Wd J, Cronkleton P et al (2010) Participatory methods for planning the future in forest communities. Soc Nat Resour 23(7):604-619. https://doi. org/10.1080/08941920802713572

18. Schlaile MP, Urmetzer S, Blok V, Andersen AD., Timmermans J, Mueller M, Pyka A (2017) Innovation systems for transformations towards sustainability? Taking the normative dimension seriously. Sustainability 9(12):2253

19. Faucheux S, Hue C (2001) From irreversibility to participation. Towards a participatory foresight for the governance of collective environmental risks. J Hazardous Mater 86(1-3):223-243. https://doi.org/10.1016/S0304-3894(01 )00260-6

20. Fogelberg H, Sandén BA (2008) Understanding reflexive systems of innovation. An analysis of Swedish nanotechnology discourse and organization. Technol Anal Strateg Manag 20(1):65-81. https://doi.org/10.1 080/09537320701726593

21. Foran T, Ward J, Kemp-Benedict EJ, Smajgl A (2013) Developing detailed foresight narratives. A participatory technique from the mekong region. E\&S 18. https://doi.org/10.5751/ES-05796-180406

22. Frittaion CM, Duinker PN, Grant JL (2010) Narratives of the future. Suspending disbelief in forest-sector scenarios. Futures 42:1156-1165

23. Fung A (2006) Varieties of participation in complex governance. Public Adm Rev 66:66-75, s1. https://doi.org/10.1111/j.1540-6210.2006.00667.x

24. Gudowsky N, Rosa A (2019) Bridging epistemologies—identifying uniqueness of lay and expert knowledge for agenda setting. Futures 109: 24-38. https://doi.org/10.1016/j.futures.2019.04.003

25. Gudowsky N, Sotoudeh M (2017) Into blue skies-a transdisciplinary foresight and co-creation method for adding robustness to visioneering. NanoEthics 11(1):93-106. https://doi.org/10.1007/s11569-017-0284-7

26. Havas A, Weber M (2018) Foresight as a governance tool to help shape the next production revolution. 2018): A múltból átívelő jövő, VIII. Magyar (Jubileumi) Jövőkutatási Konferencia 50:207-216

27. Inayatullah S (1990) Deconstructing and reconstructing the future. Futures 22(2):115-141. https://doi.org/10.1016/0016-3287(90)90077-U

28. Inayatullah S (1995) Rethinking tourism. Unfamiliar histories and alternative futures. Tourism Manag 16(6):411-415. https://doi.org/10.1016/0261-51 $77(95) 00048-5$

29. Inayatullah S (2011) City futures in transformation. Emerging issues and case studies. Futures 43(7):654-661. https://doi.org/10.1016/j.futures.2011.05.006

30. Johnson J (1979) A plain man's guide to participation. Design Stud 1(1):2730. https://doi.org/10.1016/0142-694X(79)90025-5 
31. Pierre-Benoit J, Arie R, Michael C (2010) Re-inventing Innovation. Chapters, in: Maarten J. Arentsen \& Wouter van Rossum \& Albert E. Steenge (ed.), Governance of Innovation, chapter 2, Edward Elgar Publishing

32. Jørgensen ML, Schøning S (2016) CIMULACT Deliverable 1.3. Vision Catalogue - Encompassing the visions from all 30 countries. Available online: http://www.cimulact.eu/wp-content/uploads/2018/01/CIMULACT_ VISIONS-Booklet_finalversion_lowdef-compressed.pdf. Accessed 3 Mar 202

33. Müllert N, Jungk R (1987) Future Workshops: How to create desirable futures. London, United Kingdom: Institute for Social Inventions

34. Kemmis S, McTaggart R, Nixon R (2013) The action research planner: Doing critical participatory action research. Springer Science \& Business Media

35. Kimpeler S, Schirrmeister E, Hüsing B, Voglhuber-Slavinsky A (2018) Zukunftsbilder aus dem Leben in einer Bioökonomie - Kurzfassung. Fraunhofer ISI. Karlsruhe. Available online at https://www.isi.fraunhofer.de/ content/dam/isi/dokumente/ccv/2018/Zukunftsbilder_BioKompass_Langfa ssung.pdf. Accessed 3 Mar 2021

36. Kuittinen $\mathrm{H}$, et al (2018) Mission-oriented research and innovation: Assessing the impact of a mission-oriented research and innovation approach. European Commission EC. Publications Office, Luxembourg

37. Leitner K-H (2017) The future of innovation. hyper innovation, slow innovation, and no innovation. Berg Huettenmaenn Monatsh 162(9):386388. https://doi.org/10.1007/s00501-017-0635-2

38. Leitner K-H, Weber KM (2019) Research and innovation futures. Challenging the dominant innovation paradigm. e \& i Elektrotechnik und Informationstechnik 136:226-233, 3, doi: https://doi.org/10.1007/s00502-0190728-6

39. Leitner K-H, Warnke P, Rhomberg W (2016) New forms of innovation. Critical issues for future pathways. Foresight 18(3):224-237. https://doi.org/10.1108/ FS-07-2014-0050

40. Li Z (2014) Narrative rhetorics in scenario work. Sensemaking and translation. J Futures Stud 18:77-94

41. Lindner R, Daimer S, Beckert B, Heyen N, Koehler J, Teufel B, et al (2016) Addressing directionality. Orientation failure and the systems of innovation heuristic. Towards reflexive governance. Fraunhofer ISI Discussion Papers Innovation Systems and Policy Analysis. Fraunhofer. Karlsruhe. Available online at .https://www.isi.fraunhofer.de/content/dam/isi/dokumente/cci/ innovation-systems-policy-analysis/2016/discussionpaper_52_2016.pdf. Accessed 21 Mar 2021

42. Martin BR (2010) The origins of the concept of 'foresight'in science and technology: An insider's perspective. Technol Forecasting Soc Change 77(1438-1447):9. https://doi.org/10.1016/j.techfore.2010.06.009

43. Mazzucato M (2018) Mission-oriented Research \& Innovation in the European Union. A problem-solving approach to fuel innovation-led growth. European Commission. Luxembourg. Available Online at .https://ec. europa.eu/info/sites/info/files/mazzucato_report_2018.pdf. Accessed 21 Mar 2021

44. Mazzucato M(2019a) Governing Missions in the European Union. European Comission. Luxembourg. Available online at https://ec.europa.eu/info/ publications/governing-missions-governing-missions-european-union_en. Accessed 21 Mar 2021

45. Metzger MJ, Murray-Rust D, Houtkamp J, Jensen A, la Riviere I, Paterson JS, Pérez-Soba M, Valluri-Nitsch C (2018) How do Europeans want to live in 2040? Citizen visions and their consequences for European land use. Reg Environ Change 18(3):789-802. https://doi.org/10.1007/s10113-016-1091-3

46. Miller CA, O'Leary J, Graffy E, Stechel EB, Dirks G (2015) Narrative futures and the governance of energy transitions. Futures 70:65-74. https://doi.org/10.1 016/j.futures.2014.12.001

47. Milojević I, Inayatullah S (2015) Narrative foresight. Futures 73:151-162. https://doi.org/10.1016/j.futures.2015.08.007

48. Muff K, Kapalka A, Dyllick T (2017) The gap frame-translating the SDGs into relevant national grand challenges for strategic business opportunities. Int J Manage Educ 15:363-383. https://doi.org/10.1016/j.jme.2017.03.004

49. Nelson G (2013) Future generations and climate change. Int Soc Sci J 64(89-97):211-212. https://doi.org/10.1111/issj.12039

50. Neuvonen A, Ache P (2017) Metropolitan vision making - using backcasting as a strategic learning process to shape metropolitan futures. Futures $86: 73-$ 83. https://doi.org/10.1016/j.futures.2016.10.003

51. Nikolova B (2014) The rise and promise of participatory foresight. Eur J Futures Res 2(1):109. https://doi.org/10.1007/s40309-013-0033-2

52. Peña-López I (2020) Innovative citizen participation and new democratic institutions: Catching the deliberative wave
53. Potts J (2018) Governing the innovation commons. J Institutional Econ 14(6):1025-1047. https://doi.org/10.1017/S1744137417000479

54. Ramos JM (2002) Action research as foresight methodology. J Futures Stud 7:1-24

55. Ramos JM (2006) Dimensions in the confluence of futures studies and action research. Futures 38(6):642-655. https://doi.org/10.1016/j.futures.2 005.10 .008

56. Ravetz J, Miles ID (2016) Foresight in cities. On the possibility of a "strategic urban intelligence". Foresight 18(5):469-490. https://doi.org/10.1108/FS-06-2 015-0037

57. Repo P, Matschoss K (2018) Citizen visions for European futures-methodological considerations and implications. Eur J Futures Res 6(1):33. https://doi.org/10.1186/s40309-018-0149-5

58. Rosa A, Gudowsky N, Warnke P (2018) But do they deliver? Participatory agenda setting on the test bed. Eur J Futures Res 6(1):14. https://doi.org/1 0.1186/s40309-018-0143-y

59. Rosa AB, Gudowsky N, Warnke P (2018b) Deliverable 5.2 - Report on comparison of research topics from CIMULACT with those from expert oriented foresight studies. (CIMULACT - Citizen and Multi-Actor Consultation on Horizon 2020). European Commission Grant Agreement no. 665948. Available online at https://www.researchgate.net/profile/Niklas-Gudowsky-2/ publication/333727552_CIMULACT_Deliverable_52-Report_on_comparison_ of_research_topics_from_CIMULACT_with_those_from_expert_oriented_ foresight_studies-with_annex/links/5d00f43092851c874c60ff11/CIMULACTDeliverable-52-Report-on-comparison-of-research-topics-from-CIMULACTwith-those-from-expert-oriented-foresight-studies-with-annex.pdf. Accessed 21 Mar 2021.

60. Rowe G, Frewer $\amalg$ (2005) A typology of public engagement mechanisms. Sci Technol Hum Values 30(2):251-290. https://doi.org/10.1177/01622439042 71724

61. Sandford R (2013) Located futures. Recognising place and belonging in narratives of the future. Int J Educ Res 61:116-125

62. Sanoff H (1990) Participatory design: theory and techniques. Bookmasters, Raleigh

63. Saretzki T (2012) Legitimation problems of participatory processes in technology assessment and technology policy. Poiesis Prax 9(1-2):7-26. https://doi.org/10.1007/s10202-012-0123-4

64. Saritas O, Pace LA, Staplers SI (2013) Stakeholder participation and dialogue in foresight. In: Borch K, Dingli SM, Søgaard Jørgensen M (eds) Participation and interaction in foresight. Dialogue, dissemination and visions / edited by, Kristian Borch, Sandra M. Dingli, Michael Søgaard Jøorgensen. Edward Elgar, Cheltenham, pp 35-60

65. Schirrmeister E, Warnke P (2013) Envisioning structural transformation-lessons from a foresight project on the future of innovation. Technol Forecasting Soc Change 80(3):453-466. https://doi.org/1 0.1016/j.techfore.2012.10.008

66. Schultz WL (2012) Introduction to the Symposium on Complexity, Narrative, Participation, and Images of the Future. J Futures Stud 17:107-110

67. Shearmur R, Doloreux D (2016) How open innovation processes vary between urban and remote environments. Slow innovators, market-sourced information and frequency of interaction. Entrepreneurship Region. Dev 28(5-6):337-357. https://doi.org/10.1080/08985626.2016.1154984

68. Slaughter RA (1990) The Foreisght principle. Futures 22(801-819):8. https:// doi.org/10.1016/0016-3287(90)90017-C

69. Sotoudeh M, Gudowsky N (2018) CIVISTI_-a forward-looking method based on citizens' visions. fped 5:73. https://doi.org/10.14746/fped.2016.5.2.22

70. Stilgoe J, Owen R, Macnaghten P (2013) Developing a framework for responsible innovation. Res Policy 42(9):1568-1580. https://doi.org/10.1016/j. respol.2013.05.008

71. Störmer E, Truffer B (2009) Strategic decision making in infrastructure sectors. Participatory foresight and strategic planning for sustainable sanitation. Geogr Helvetica 64(2):73-80. https://doi.org/10.5194/gh-64-73-2009

72. Trist, Eric, L. (2012) Action research and adaptive planning. In: Clark AW (ed) Experimenting with Organizational Life. The action research approach. Springer US, Boston, pp 223-236

73. Tuckett D (2018) Conviction narrative theory and understanding decisionmaking in economics and finance. Uncertain Futures: Imaginaries, Narratives and Calculation in the Economy, pp 62-82

74. Tukker A, Tischner U (2006) Product-services as a research field: past, present and future. Reflections from a decade of research. 14, Issue 17, 1552-1556. J Cleaner Prod 14:1552-1556, doi: 10.1016/j.jclepro.2006.01.022 
75. UN General Assembly, Transforming our world: the 2030 Agenda for Sustainable Development, 21 October 2015, A/RES/70/1. Available at: https://www.refworld.org/docid/57b6e3e44.html. Accessed 21 Mar 2021.

76. UNDPI (2009) Millennium development goals report 2009. United Nations Publications, Geneva. Available online at https://www.un.org/millenniumgoa Is/pdf/MDG_Report_2009_ENG.pdf. Accessed 21 Mar 2021

77. Verheul H, Vergragt PJ (1995) Social experiments in the development of environmental technology: a bottom-up perspective. Technol Anal Strateg Manage 7(3):315-326. https://doi.org/10.1080/09537329508524215

78. Voss J-P, Bauknecht D, Kemp R (2006) Reflexive governance for sustainable development. Edward Elgar, Cheltenham, Northampton, doi: https://doi. org/10.4337/9781847200266

79. Voss J-P, Bauknecht D, Kemp R (eds) (2006) Reflexive governance for sustainable development. Edward Elgar Publishing. https://doi.org/10.4337/ 9781847200266

80. Warnke P, Koschatzky K, Dönitz E, Zenker A, Stahlecker T, Som O, et al. (2016) Opening up the innovation system framework towards new actors and institutions. Fraunhofer ISI Discussion Papers Innovation Systems and Policy Analysis. Available online at https:/www.isi.fraunhofer.de/content/da m/isi/dokumente/cci/innovation-systems-policy-analysis/2016/discussionpa per_49_2016.pdf. Accessed 21 Mar 2021

81. Warnke P, Schirrmeister E (2018) Transition-scenarios towards socially sustainable global value chains: Insights from the SONA WSK Foresight (No. S10/2018). Working Paper Sustainability and Innovation. Available online at https://www.econstor.eu/handle/10419/181877. Accessed 21 Mar 2021

82. Widener MN (2013) Moderating Citizen Visioning in Town Comprehensive Planning: Deliberative Dialog Processes. Wayne L. Rev., 59, 29.w. Available online at https://heinonline.org/HOL/LandingPage?handle=hein.journals/wa ynlr59\&div=6\&id=\&page $=$. Accessed 21 Mar 2021

83. Weber MK (2006) Foresight and adaptive planning as complementary elements in anticipatory policy making. A conceptual and methodological approach. In: Voss J-P, Bauknecht D, Kemp R (eds) Reflexive governance for sustainable development. 189-217. Edward Elgar, Cheltenham Glos

84. Weber KM, Rohracher $\mathrm{H}$ (2012) Legitimizing research, technology and innovation policies for transformative change. Res Policy 41(6):1037-1047. https://doi.org/10.1016/j.respol.2011.10.015

85. Metzger MJ, Murray-Rust D, Houtkamp J, Jensen A, La Riviere I, Paterson JS, Pérez-Soba M, Valluri-Nitsch C (2018) How do Europeans want to live in 2040? Citizen visions and their consequences for European land use. Regional Environmental Change 18(3):789-802

86. Georghiou L, Tataj D, Celi J, Giannini S, Pavalkis D, Verganti R, Renda A (2017) Mission-oriented Research and Innovation Policy: A RISE Perspective. European Commission, Luxembourg. Available online at https://ec.europa. eu/info/sites/info/files/mission_oriented_r_and_i_policy-a_rise_perspective. pdf. Accessed 21 Mar 2021

\section{Publisher's Note}

Springer Nature remains neutral with regard to jurisdictional claims in published maps and institutional affiliations.

\section{Submit your manuscript to a SpringerOpen ${ }^{\circ}$ journal and benefit from:}

- Convenient online submission

- Rigorous peer review

- Open access: articles freely available online

- High visibility within the field

- Retaining the copyright to your article

Submit your next manuscript at $\boldsymbol{\nabla}$ springeropen.com 